\title{
OS EFEITOS DA MUSICOTERAPIA EM PACIENTES PSICÓTICOS - UMA \\ REVISÃO DE LITERATURA
}

Clarice Dalsotto de Melos ${ }^{1}$

Magda Medianeira de Mello

Resumo: A proposta do presente estudo tem como objetivo a investigação, através de uma revisão da literatura, dos efeitos psíquicos produzidos pela musicoterapia em pacientes de estrutura de personalidade psicótica. Utilizou-se o referencial psicanalítico no que tange aos conceitos da formação do psiquismo, suas patologias e como os elementos da musicoterapia se apresentam como possibilidade nas intervenções terapêuticas, visto que a música propicia a produção de um material simbólico na experiência subjetiva do sujeito. Concluiu-se que o trabalho com música beneficia os indivíduos psicóticos, principalmente no que tange à interação social, ao lazer e, principalmente, à inauguração de marcas de satisfação e registros no psiquismo.

Palavras-chave: Musicoterapia; Psicose; Autismo; Psicanálise.

THE EFFECTS OF MUSIC THERAPY ON PSYCHO PATIENTS - A LITERATURE REVIEW

\begin{abstract}
The aim of this study was the investigation, through literature review, of the psychic effects produced by musical therapy on patients with psychotic personality structure. A psychoanalytic referential was used regarding the concepts of psyche formation, its pathologies and how musical therapy elements present themselves as a possibility in therapeutic interventions, since music provides the production of symbolic material on the subject's subjective experience. Therefore, it is concluded that working with music benefits
\end{abstract}

\footnotetext{
${ }^{1}$ Acadêmica do Curso de Bacharelado em Psicologia da UNICNEC.

${ }^{2}$ Doutora em Psicologia pela Universidad Autònoma de Madrid.

Perspectiva: Ciência e Saúde,Osório, V. 4 (2): 153-171, Dez 2019.
} 
psychotic individuals, specially with regard to social interaction, leisure and, mainly, the inception of marks of satisfaction and records in the psyche.

Keywords: Musical therapy; Psychosis; Autism; Psychoanalysis.

\section{INTRODUÇÃO}

A proposta do presente estudo, intitulado "Os Efeitos da Musicoterapia em Pacientes Psicóticos: Uma Revisão de Literatura", tem como objetivo investigar os efeitos psíquicos ocasionados pela terapêutica musicoterápica, em pacientes psicóticos.

A psicose consiste, em sua gênese, na ruptura do ego com o mundo externo, em que o fator determinante e predominante do modo de ser, agir e pensar (a personalidade) do indivíduo, são influenciados diretamente pelo $i d$. Dessa forma, a psicose passa a reparar a perda da realidade pela criação de uma nova que não levanta as mesmas objeções que a antiga (Freud, 1924), visto que, conforme Santos e Oliveira $(2012$, p. 3) “...tanto a neurose quanto a psicose traduzem o fracasso do eu em conciliar as exigências pulsionais e as da civilização, relativas às frustrações que marcam a vida infantill”.

No que tange ao diagnóstico de psicose, retirou-se da quinta revisão do Manual Diagnóstico e Estatístico de Transtornos Mentais (DSM), referências de pressupostos teóricos e psicodinâmicos de uma ou outra abordagem da psicologia e psiquiatria, a fim de basear a classificação em sintomas que pudessem ser observados e quantificados (Tenório, 2016). O termo "psicose" sofreu fragmentação no DSM-5, "esquizofrenia e outros transtornos psicóticos" (Pontes e Calazans, 2017). Caracteriza-se, portanto, empiricamente por "anormalidades em um ou mais dos cinco domínios: delírios, alucinações, pensamento (discurso) desorganizado, comportamento motor grosseiramente desorganizado ou anormal (incluindo catatonia) e sintomas negativos.”(DSM-5, p. 87).

A psicanálise sustenta a validade clínica da psicose desde o seu início, com o estudo e conceituações iniciados em Freud, baseados na prática do autor no trabalho das neuroses para com as pacientes histéricas. Para Freud (1896, p. 106), as alucinações de pacientes neuróticas configuravam-se como "partes do conteúdo de suas experiências infantis recalcadas, ou seja, sintomas do retorno do recalcado". No que segue, em 1911, Freud publica o Caso Schreber, onde analisa o livro autobiográfico Memórias de Um Doente dos Nervos, de Daniel Paul Schreber (1903). A obra contém o relato de como se construiu/revelou a psicose de Schreber, 
bem como a evolução clínica de seus sintomas, principalmente no campo dos delírios (Freud, 1911).

Atualmente, após evoluções nos dispositivos de tratamento de indivíduos psicóticos, oportunizadas por estudos de diversos seguimentos da psicologia e da psiquiatria, atenta-se aos locais de circulação desses indivíduos que, antes enclausurados em instituições psiquiátricas, hoje se estendem para outros setores da sociedade com ênfase na estruturação dos Centros de Atenção Psicossocial (CAPS). Estas unidades oportunizam a obtenção de tratamento médico e psicológico, associadas com a inserção dos indivíduos na sociedade e atividades que permitam a interação em grupo, desenvolvimento de habilidades e autonomia dentro de sua própria comunidade.

Dentre as variedades terapêuticas possíveis no tratamento e promoção de saúde, que podem estar inseridas em CAPS, clínicas privadas e demais instituições, encontra-se a musicoterapia, que possui propriedade para estimular a subjetividade e associações livres através da música e demais práticas de seus elementos.

A musicoterapia é uma abordagem terapêutica utilizada em tratamento e apoio em saúde mental que se apresenta como uma interseção de várias áreas do conhecimento, em que se relacionam o ser humano e a música, num encontro que abarca arte, ciência e saúde (Piazetta, 2007). Segundo a Federação Mundial de Musicoterapia (1996, p. 1), a atividade consiste em uma "intervenção que utiliza a música e seus elementos, por uma pessoa qualificada, para promoção de aprendizagem, aquisição de novas habilidades, a fim de proporcionar melhor qualidade de vida".

Dessa forma, a musicoterapia tem como objetivo a promoção de saúde e ganhos terapêuticos através da comunicação, expressão e aprendizado de seus elementos, proporcionando assim, possibilidades de interação, sublimação e contato com sua subjetividade, podendo ser aplicada como prevenção, reabilitação ou tratamento.

Assim sendo, pensa-se a musicoterapia como uma forma de contribuir para o plano terapêutico do indivíduo psicótico, visto que vai ao encontro da proposta atual da atuação humanizada nos ambientes de saúde, em que se busca atentar para os cuidados que concernem à doença, à cura e ao tratamento, mas também às demandas psicológicas do paciente (Crepaldi et al., 2006), tais como emoções, sentimentos, possibilidades de associação livre e sublimação, dentre outros, justificando, para maior entendimento destes, a revisão de literatura. 


\section{FUNDAMENTAÇÃO TEÓRICA}

\subsection{Aspectos Técnicos da Musicoterapia}

A Musicoterapia como formação surge durante a segunda guerra mundial, nos Estados Unidos, após médicos começarem a notar significativos resultados de veteranos de guerra, que passavam por sessões onde escutavam músicas nos hospitais (Godoy, 2014), percebendo-se então, a sua importância como um elemento que oportuniza a interação e a flexibilização dos processos do sofrimento, visto que promove a livre expressão destes. A terapêutica musicoterápica adquire seu espaço através da união da música, psicologia, psiquiatria, psicopedagogia, educação e diversas outras áreas que são entendidas como constituição do ser humano e facilitadoras de sentimentos e emoções (Godoy, 2014).

Objetivando o desenvolvimento de potenciais presentes em cada um de nós, a musicoterapia utiliza-se do som, ritmo, melodia, harmonia e diversas técnicas de representação musical trabalhadas individual e coletivamente; entretanto, não corresponde simplesmente a utilização da música mas, sim, das experiências musicais, sendo então o agente da terapia não visto apenas como a música (isto é, um objeto externo ao paciente), mas sua experiência (interação entre pessoa, processo, produto e contexto) com ela; postula, portanto, que o papel do Musicoterapeuta vai além de prescrever e ministrar a música mais apropriada; ele também envolve desenvolver a experiência do cliente com aquela música (Bruscia, 2000). A música claramente ajuda a aprofundar relações e vínculos, pois é oferecida a oportunidade de compartilhar experiências criativas com sons e silêncios, tornando as atitudes mais positivas entre os envolvidos (Oldfield, 2006).

A música como terapêutica, configura-se substancialmente como uma possibilidade humanizada do cuidado, experienciando tanto os pacientes quanto equipe, uma abordagem leve e diferente, porém intensas, em suas práticas dentro dos planos terapêuticos. Ressalta-se, novamente, a importância de que o profissional esteja capacitado para perceber e lidar com sentimentos existentes, que normalmente emergem durante atividades que utilizam música (Valentin et al, 2013).

A musicoterapia trata-se de uma ciência e uma terapêutica com metas e objetivos bem definidos, temporalmente organizados, com uma metodologia e um corpo de conhecimento composto por uma variedade de teorias e contínua pesquisa. É, portanto, uma profissão que 
possui padrões clínicos e éticos que orientam e regulam a conduta dos profissionais musicoterapeutas (Bruscia, 2000).

Outro significativo elemento da técnica nas atividades musicoterapêuticas, refere-se ao respeito pela escolha do paciente, pois esta é relacionada à sua identidade musical, podendo promover bem-estar e conforto. Quando isso não ocorre, pode funcionar como fator estressante ou desencadear momentos de tensão (Valentin et al, 2013).

Embora se tratando de um estímulo sonoro musical, o tratamento musicoterapêutico não apresenta exigências no que tange a habilidades e conhecimentos prévios do paciente para com a música, mas sim da formação e orientação metodológica do terapeuta, tornando-se sempre importante avalizar que a intervenção que se utiliza da musicoterapia deve ser somente realizada por um profisssional capacitado, seja pelo curso de graduação ou especialização na área, a fim de diferenciar a prática de uma simples atividade musical.

A saber, nos itens que seguem abordaremos o ritmo interno dos sujeitos nas suas subjetividades, bem como sua ligação nos processos da psicose pela perspectiva psicanalítica.

\subsection{O Ritmo que Inaugura a Vida Psíquica}

São nas fases mais primitivas e arcaicas do desenvolvimento humano que se instauram aspectos importantes para a organização (ou desorganização) da vida psíquica que está se constituindo. O processo de subjetivação ocorre desde o início da vida do bebê, onde, ainda na gestação, lhe é atribuído um nome, o lugar e o papel que este desempenhará na família. O sucesso de tal processo depende de diversos fatores, mas, se tratando de estrutura psíquica, alguns deles merecem uma especial atenção.

Durante o primeiro ano do bebê, há habilidades e comportamentos esperados a fim de se constatar que está se desenvolvendo de forma saudável; a motricidade, o olhar, sorrir, brincar e reconhecer a presença e voz da mãe são alguns exemplos. A função materna é de extrema importância para acolher o bebê e proporcionar-lhe os primeiros estímulos responsáveis pela constituição do aparelho psíquico, e é nesse jogo sensorial da mãe com o bebê que se inicia um ritmo, de forma que cada díade, tríade ou cada família dota esse bebê com o ritmo que o ajudará a se constituir como sujeito (Guerra, 2017).

Segundo Guerra (2017, p. 44), “o ritmo é também a experiência que, partindo de uma espécie de "caos" inicial, dá forma, organização temporal e tem como função abrir para a 
terceiridade, abrir para o outro". O ritmo estabelece as conexões do bebê com o ambiente, de modo que seu processo de subjetivação depende da funcionalidade desse ritmo, pois sua função delimitante tem grande relevância nos contornos do self, numa crescente diferenciação eu/não-eu e na construção de um espaço interno para representar (Martins e Giaretta, 2017); as autoras também ressaltam que em um contexto de tratamento, para ser terapêutico, o ritmo deve ser co-criado com o paciente, em uma ritmicidade conjunta.

No que tange ao ritmo perante a organização das funções materna e paterna, Guerra (2017) avaliza que o processo de subjetivação do bebê dependerá da integração rítmica adequada da lei materna do encontro com a lei paterna da separação, alternando-se em um ritmo que cada família organiza pois, não se pode haver união sem perspectiva de separação, bem como separar o que não se uniu.

O ritmo se constitui através da intersubjetividade do bebê com o ambiente, ou seja, sua constituição subjetiva que se dá pela comunicação multissensorial com a subjetividade do outro (sujeito e/ou objeto). O conceito de intersubjetividade vem sendo estudado pela sua relação com o desenvolvimento infantil inicial, de forma que Nogueira e Moura (2007, p. 137) apresenta que “...inata ou não, a intersubjetividade envolve um processo que somente se desenvolve e se complexifica se houver um contexto de troca com outro", ou seja, através da comunicação mãe-bebê, principalmente em seu primeiro ano de vida.

Dessa forma, o ritmo da comunicação intersubjetiva do bebê com o meio, com ênfase na união com a mãe e a sustentação dessa união pelo pai, tende a propiciar o sucesso dos primeiros passos da organização do aparelho psíquico primitivo, a fim de que, após esta primeira etapa, se possa adquirir novas organizações rítmicas mais elaboradas compatíveis com as próximas fases do desenvolvimento psicossexual.

Quando há uma disfuncionalidade do ritmo mãe e bebê, a exemplo da relação simbiótica e da incapacidade do pai de entrar e separar a dupla, ocorre a constituição da singular estrutura psíquica da psicose, abordada no capítulo a seguir.

\subsection{A Psicose na Perspectiva Psicanalítica}

Ao iniciar as considerações sobre a psicose, é importante salientar que o mecanismo de defesa principal é a foraclusão (cisão), ou seja, a recusa à realidade, sendo característica a 
substituição desta pelo delírio. Entende-se por mecanismos de defesa do ego, os processos subconscientes desenvolvidos pela personalidade, os quais possibilitam a mente desenvolver uma solução para conflitos e frustrações não solucionados a ao nível da consciência (Silva, 2010). O afastamento da realidade pelo psicótico aponta para um distúrbio no relacionamento entre o ego e o mundo externo, de forma que, conforme apresentado por Freud (1923),

\footnotetext{
O ego cria, automaticamente, um novo mundo externo e interno, e não pode haver dúvida quanto a dois fatos: que esse novo mundo é construído de acordo com os impulsos desejosos do id e que o motivo dessa dissociação do mundo externo é alguma frustração muito séria de um desejo, por parte da realidade — frustração que parece intolerável. (p. 87)
}

Pensando nas instâncias psíquicas id, superego e ego, o id é responsável pelos desejos e paixões, a fim de serem satisfeitos sem barreiras e sem censura; o superego corresponde às exigências sociais, tais como as leis da sociedade e questões éticas e morais; por sua vez, o ego é a instância psíquica que deve realizar o manejo entre as pulsões do id e as solicitações do superego. É o desenvolvimento psicossexual do indivíduo que determinará como irão se portar as três instâncias psíquicas, determinando como o sujeito se movimentará durante sua vida, sua estrutura de personalidade e sua relação com a realidade.

$\mathrm{Na}$ neurose, o recalcamento secundário é o mecanismo de defesa que fundamenta a patologia, sendo a gene dos sintomas neuróticos e configurando-se como a negação simbólica dos desejos ocorridos no interior do eu, de forma que tais desejos não sejam explanados ao exterior da consciência. Dessa forma, Freud (1917, p. 25) postula que “...a neurose poderia equivaler a uma doença traumática, e apareceria em virtude da incapacidade de lidar com uma experiência cujo tom afetivo fosse excessivamente intenso".

Em uma neurose, será na medida em que a realidade não é plenamente re-articulada de maneira simbólica no mundo exterior, que há no sujeito a fuga parcial da realidade e/ou incapacidade de enfrentar uma parte da realidade, secretamente conservada. Na psicose, ao contrário, é realmente a própria realidade que é em primeiro lugar provida de um buraco, que o mundo fantástico virá em seguida cumular. (Lacan, 1955-1956/1985). Dessa forma, pensa-se a psicose, além de uma estrutura (des)organizadora da personalidade do indivíduo, mas como a orientação do próprio indivíduo, no que tange ao seu trato com o real/imaginário e sua maneira de se colocar no mundo, pois entra em conflito com o externo, instaurando-se no sujeito psicótico uma relação de exterioridade diante da realidade da linguagem (Lacan, 
1955-56/1998). Dessa forma, o estado do sujeito, tanto na neurose como na psicose, depende do que se desenrola no campo do Outro e no campo da linguagem (Meyer, 2008).

No trabalho com as psicoses, o analista busca sustentar significantes do sujeito capazes de dar contorno ao real e a este sujeito que vive às bordas da loucura e que pode, a qualquer momento, despencar no furo da psicose (Herrmann, 2004). Neste sentido, pensa-se na construção de condições para que o sujeito possa produzir cada vez mais possibilidades de ser e estar no mundo a partir de sua singularidade.

\subsection{Patologias Graves a Exemplo do Autismo}

A diferenciação entre as condições do autismo e da psicose infantil acarretam estudos na área da psicanálise. Entendidas muitas vezes como semelhantes pela psiquiatria, Jerusalinsky (1993) postula suas diferenças através do entendimento do autismo como uma quarta estrutura psíquica ao lado das já fundamentadas - psicose, neurose e perversão, de forma que, também, seu mecanismo de defesa do ego se apresenta como singular: a exclusão. Segundo o autor, na exclusão não há inscrição do sujeito; no lugar onde a inscrição deveria se encontrar, se encontra o Real, ou seja, a ausência de inscrição (Jerusalinsky, 1993).

Como facilitador do entendimento, propõe-se, como o faz Jerusalinsky, uma forma de diferenciar psicose de autismo nos seguintes termos: no autismo, falha a função materna; na psicose, falha a função paterna (Kupfer, 2000), acarretando, então, fracassos graves na constituição psíquica e no desejo do adulto.

O autismo é um efeito do modo em que é produzida a introdução do indivíduo da espécie humana no campo do Outro, no campo da linguagem. O modo particular em que é introduzido um indivíduo da espécie humana para vir a produzir o autismo, é sob o modo da exclusão do campo do significante (Jerusalinsky, 2011).

No que segue, o autismo apresenta-se como uma das condições da experiência humana que mais vem sofrendo variações em sua conceituação, sendo atualmente, o DSM-V, o manual classificatório amplamente utilizado para elucidar seu conceito e seus critérios diagnósticos, estando incluído na categoria de transtornos do neurodesenvolvimento.

Muito se discute nas áreas clínicas e acadêmicas a respeito de sua causa, dessa forma, a etiologia do autismo é proveniente de uma deficiência na constituição do ego, consistindo 
numa interrupção no desenvolvimento do sujeito devido a uma adaptação falha às suas necessidades, obrigando-o a reagir de forma a se fechar para as experiências externas, percebidas como invasivas, perdendo o sentido de self adquirido até então (Marfinati e Abrão, 2014).

Assim como a psicose, estruturas psíquicas desviantes da "normalidade" demandam estudos cada vez mais aprofundados. A psicanálise se debruça a investigar, a partir de seus achados, um caminho para o entendimento da origem das patologias graves da subjetivação, bem como dispositivos terapêuticos tanto para trabalhar no âmbito da prevenção quanto para o tratamento da estrutura psíquica já estabelecida. É válido lembrar que apenas no início do século XX temos o surgimento de uma verdadeira psicopatologia da infância, fortemente influenciada pela psicanálise (Rose e Lucero, 2018).

O psiquiatra austríaco Leo Kanner foi pioneiro ao se tratar dos estudos com o autismo, identificando as particularidades da patologia em sua clínica. Segundo Seincman (1997), Kanner refere que, desde o início, o autista desdenha, ignora e exclui o que lhe vem de fora e que esta é uma patologia em que há uma incapacidade da criança em estabelecer, precocemente, relações e reagir normalmente às pessoas e situações, sendo característico o fechamento e as estereotipias, ou seja, comportamentos e falas repetitivos sem uma intenção comunicativa.

Silvia Bleichmar, psicanalista e estudiosa renomada das psicoses infantis, salienta o cuidado que deve-se despender ao diagnóstico do autismo, visto que grande parte da regulação do que é chamado transtornos do desenvolvimento são transtornos na constituição do sujeito psíquico (constituição do ego, da personalidade psíquica, da temporalidade), que estão relacionados com a exteriorização e estrutura do ego no interior da tópica, com a capacidade relacional (Molloy, Ferreira/Bleichmar, 2001).

$\mathrm{O}$ atendimento psicológico com o sujeito autista demanda do terapeuta um relevante entendimento da complexidade do desenvolvimento humano e suas formas de experienciar o mundo através de sua singularidade psíquica. A avaliação e a intervenção terapêutica em casos de autismo de psicose devem pautar-se nas possibilidades que o sujeito terá para movimentar-se pelo mundo.

Segue a necessidade de continuidade de estudos na área da clínica infantil a fim de traçar cada vez mais estratégias de entendimento e tratamento da condição do autismo, de 
forma que, como aponta Bleichmar (2001, p. 202) “...as grandes transformações na Psicanálise surgem da análise das crianças ou das psicoses”.

\subsection{Considerações da terapêutica musicoterápica na psicose}

No que se refere ao trabalho clínico e psicossocial com as psicoses, torna-se importante não somente a posição investigadora e pragmática do terapeuta, mas a empática e flexível, visto que a própria psicose nos ensina sobre sua estrutura, sua lógica, indicando-nos o caminho de escuta que devemos seguir, por meio das soluções que ela mesma encontra para lidar com a falta estrutural do significante paterno (Meyer, 2008). Dessa forma, a musicoterapia na psicose deve considerar, acima de tudo, o sujeito biopsicossocial que ali se encontra, em toda a sua singularidade e compreensão (e formação) ímpar da realidade, podendo vir a contribuir na ampliação e sublimação desta.

Durante um trabalho com musicoterapia, principalmente em grupo, são várias as expressões (sonoras e não sonoras), comportamentos e relacionamentos que se entrelaçam, se interpenetram, proporcionando aos integrantes do grupo reviver, no âmbito terapêutico, recortes de experiências de vida com suas nuances (Valentin et al, 2013). Isto posto, salienta-se a importância da valorização dessas experiências no campo da psicose onde, no encontro com o outro (real) o indivíduo psicótico possa, junto às experiências sensoriais proporcionadas pela musicoterapia, tecer novas teias em uma trama adaptativa do real, realizando, através destas, a simbolização.

Segundo Sampaio (2005, p. 22), a música apresenta-se como “...uma forma do homem entender, organizar, classificar, interagir, manipular, ser manipulado, construir, desconstruir, enfim, uma forma de se relacionar com o mundo", sendo então, uma forma histórica de integração com o seu meio e seus pares, através não da materialização, mas da experiência. Os sons vêm da natureza, mas a música é o homem quem a faz, pois a música não é um objeto, mas sim uma ação do homem sobre o mundo (Puchivailo e Holanda, 2014).

Assim sendo apresentado, a musicoterapia vem a realizar resultados promissores no trabalho psicossocial com indivíduos de estrutura de personalidade psicótica, visto que vem a integrá-lo num grupo funcional e promotor de saúde, que valoriza e estimula sua restrita capacidade de simbolização e suas prévias experiências, criando laços (e não nós) em seus 
fragmentados processos de subjetividade. Para isso, é imprescindível o terapeuta estar articulado com as peculiaridades da estrutura, visto que o desejo do analista possibilita a transferência com a abertura de um espaço para o sujeito, sustentando uma existência possível (Meyer, 2008).

O som é a relação primária com o mundo, desde o ventre materno. A mãe canta para seu bebê e, o bebê, já no período sensório-motor, reconhece sua voz, sua vibração, seu som. A conexão multissensorial da mãe e seu bebê configura-se como uma das possibilidades do olhar do grande outro. O espelho, para além do desejo é, como a música, uma experiência sensorial, e é no trabalho com essas experiências que se oportunizará de reprodução do desejo materno, por onde o psicótico poderá construir-se como sujeito e autônimo de sua melodia e sua vida.

Dessa forma, de qual modo virá a se pensar a musicoterapia aplicada à saúde mental e a promoção de efeitos no psiquismo de indivíduos psicóticos? Ora, visto que a utilização da música não se dá como um instrumento/elemento comercial, material e temporal, mas como um dispositivo promotor e intensificador de experiências multissensoriais, é, nessa vivência, que une-se o concreto com o simbólico, que se iniciará o contato de indivíduos de estrutura psíquica regressiva; é através das técnicas que o ego flexibilizará a concretude dos fatos, estimulando a simbolização das experiências, sejam elas individuais ou coletivas, subjetivas ou interacionais: traz-se o dentro de si (autismo) para fora, onde o foracluído, inclui-se.

\section{METODOLOGIA}

O presente estudo trata-se de uma pesquisa qualitativa de cunho exploratório, as quais proporcionam uma visão geral, de tipo aproximativo, acerca de determinado tema de interesse do investigador, em que habitualmente envolve levantamento bibliográfico (Gil, 2008). "Este tipo de pesquisa tem como objetivo proporcionar maior familiaridade com o problema, com vistas a torná-lo mais explícito ou a construir hipóteses" (Gerhardt e Silveira, 2009, p. 35). O viés de investigação utilizado foi o psicanalítico.

A base de dados utilizada na busca foi através do portal eletrônico SCielo. Além disto, artigos relevantes para a revisão foram buscados nas referências dos estudos que fecharam critérios para a inclusão na revisão. Os descritores utilizados na investigação foram: (1) 
musicoterapia; (2) psicose (3) efetividade e (4) autismo. Foram incluídos na pesquisa artigos científicos que apresentaram considerações a respeito das respostas psíquicas em pacientes psicóticos que foram expostos ao tratamento com musicoterapia, bem como pesquisas clássicas e atuais que expuseram as conceituações a respeito da formação das estruturas psíquicas e seus mecanismos de defesa pela linha teórica da psicanálise. Os artigos excluídos foram aqueles que não apresentem respostas dos efeitos psíquicos de tal tratamento, bem como se essas respostas se tratarem de outro tratamento que não a musicoterapia ou com música, ou em pacientes que não apresentem estrutura psicótica.

\section{RESULTADOS E DISCUSSÃO}

Este artigo procurou investigar possíveis efeitos no psiquismo de pacientes psicóticos proporcionados pela musicoterapia, cuja problemática levantada foi se a técnica produz benefícios em pacientes com estrutura de personalidade psicótica. Para solucionar essa questão, foi utilizado o referencial psicanalítico no que consiste à formação do psiquismo de indivíduos psicóticos bem como conceituações sobre as patologias, e como os elementos musicoterápicos tendem a contribuir no desenvolvimento nos processos da subjetividade.

No que diz respeito à relação mãe-bebê, "...o bebê, desde o momento do nascimento, é capaz de reconhecer os padrões sonoros da voz de sua mãe, manifestando preferência por ela" (Lima, 2012, p. 16). Tal acolhida multissensorial do sujeito psíquico é representada pelo manhês, ou seja, a forma melodiosa, ritmada, sintonizada e suave da voz que a mãe, ou quem exerça a função materna, endereça ao bebê, bem como a resposta do bebê no processo de comunicação da díade (Flores, Bealtrami e Souza, 2011). Os resultados da pesquisa das autoras sugerem que o manhês é elemento fundamental na detecção de riscos no desenvolvimento infantil, fazendo com que esse elemento da relação mãe-bebê seja de extrema relevância para o psiquismo.

Nas patologias graves, nota-se que mesmo em casos de intenso comprometimento no laço social, a musicalidade é capaz de promover ou facilitar uma conexão, ainda que efêmera (Lima e Lerner, 2016), apresentando-se, então, como possibilidade de entrar no território do outro para o trabalho terapêutico. Isto posto, a musicoterapia também requer atenção devendo-se levar em consideração a potência da música, tanto para desorganizar, isolar ou gerar sofrimento, quanto para auxiliar em uma organização,possibilitar experiências de 
inclusão e acolher o sofrimento (Puchivailo e Holanda, 2014). Salienta-se aqui, que o sucesso ou o fracasso da atividade ocorrerá em conformidade com a capacitação do profissional, que deverá possuir sensibilidade na escolha dos elementos musicais utilizados.

A autoras Lima e Poli (2016) sustentam a hipótese de que a música se mostra uma via potente na criação de intervalos entre o sujeito e o Outro, o que é desafio constante nessa clínica, pontuando a importância do silêncio como representante deste intervalo.

A relação familiar benéfica para o saudável desenvolvimento psíquico do bebê, é sustentada por Guerra (2017, p. 48) ao nos apresentar graficamente que "...são necessários três para que dois tenham a ilusão de ser um", pontuando a importância da ritmicidade entre a função materna e paterna.

$\mathrm{Na}$ infância, "...a música, dotada de significantes, faz com que a criança recorde momentos arcaicos de seu desenvolvimento, convidando-a a entrar em contato com outro, com sua diferença e com sua alteridade" (Souza et al 2017, p. 314), suportando, então, tanto a entrada do outro, como o intervalo entre si e o outro.

Procurou-se apresentar conceituações de musicoterapia e sua aplicação nos contextos de tratamento; escrever, de acordo com a literatura psicanalítica, considerações a respeito da psicose bem como sua constituição; e identificar possíveis benefícios terapêuticos da musicoterapia em indivíduos psicóticos.

Através dos resultados da pesquisa, concordamos com Lima (2012), em que a atenção à dimensão musical, seja na fala ou movimentos, é profícua para o trabalho com pacientes com distúrbios de desenvolvimento como o autismo e, principalmente, a psicose.

Salienta-se as dificuldades em encontrar artigos que apresentem as reais conceituações da musicoterapia (ciência e profissão) no tratamento das patologias psíquicas, visto que as publicações abordam em maior quantidade as oficinas, principalmente em instituições de saúde mental, que se utilizam de atividades com música; da mesma forma, tais atividades tendem a trazer benefícios aos indivíduos psicóticos, principalmente no que tange à interação social e ao lazer, já que há, principalmente, a inauguração de marcas de satisfação e registros no psiquismo Segue a necessidade de se pensar e publicar cada vez mais pesquisas e publicações aplicadas na área. 


\section{CONSIDERAÇÕES FINAIS}

Conforme elaborado no presente estudo, a musicoterapia surge no trabalho com egressos de guerra, onde percebeu-se que o contato com a música e seus elementos facilitavam a recuperação de soldados, pois permitiam expressar suas experiências traumáticas no campo de batalha, flexibilizando assim, suas possibilidades de reintegração e expressão do sofrimento e patologias desenvolvidas.

A musicoterapia possui suas técnicas próprias e deve ser efetivamente reconhecida como ciência e profissão, visto que surge da união de diversas teorias do trabalho com o que é humano e, a partir daí, desenvolvida em estudos e aplicações científicas, inclusive no trabalho com a psicose.

Nesse estudo, elucida-se o conceito da estrutura de personalidade psicótica, em que, para além de elementos teóricos, é na experiência subjetiva da estrutura que ela mesma nos ensina sobre sua formação e organização. Sem censura, o id, instância psíquica responsável pelos impulsos desejosos do indivíduo, ao confrontar-se com o mundo externo, ignora-o, criando um novo para si, a partir de suas paixões, por isso são frequentes, por exemplo, alterações da sensopercepção, como as alucinações, e do pensamento, como os delírios.

$\mathrm{Na}$ terapêutica musicoterápica, torna-se primordial que o terapeuta valorize o indivíduo como ser biopsicossocial e respeite suas experiências, muitas vezes somente no campo do concreto, característica básica dessa estrutura. É com o trabalho musicoterapêutico, que o sujeito psicótico poderá adentrar ao campo da música e ter contato com seus elementos, como o som, a melodia, os diferentes instrumentos, as letras musicais, o silêncio, as pausas, os diferentes tipos de música e etc, a fim de se produzir um material simbólico na experiência subjetiva dos sujeitos, bem como mais uma possibilidade de integração positiva com o meio e com o real.

Trata-se de um tema relevante para se pensar cada vez mais propostas de intervenção de modo a adentrar o campo concreto e restrito da estrutura; o presente artigo ilustra a problemática da musicoterapia para psicóticos de forma objetiva e ao mesmo tempo utilizando o referencial psicanalítico para ampliar o entendimento da singularidade do sujeito, que se utiliza da música para atingir uma "cura" psíquica. 


\section{REFERÊNCIAS BIBLIOGRÁFICAS}

BRUSCIA, K. E. Definindo Musicoterapia. Rio de Janeiro: Enelivros, 2000.

CREPALDI, M. A. LINHARES, B. M. PEROSA, G. B. (2006). Temas em psicologia pediátrica. São Paulo: Casa do Psicólogo, 2006.

Federação Mundial de Musicoterapia. Definição de Musicoterapia. Revista Brasileira de Musicoterapia. Rio de Janeiro: UBAM, Ano I, 2, 1996.

FLORES, M. R.; BELTRAMI, L. SOUZA, A. P. O manhês e suas implicações para a constituição do sujeito na linguagem. Revistas Distúrbios da Comunicação. São Paulo, 2011.

FREUD, S. Primeiras publicações psicanalíticas (1893-1899).Edição standard brasileira das obras psicológicas completas de Sigmund Freud, Vol. 3. Disponível em http://conexoesclinicas.com.br/wp-content/uploads/2015/01/freud-sigmund-obras-co mpletas-imago-vol-03-1893-1899.pdf.

FREUD, S. O caso Schereber, artigos sobre técnica e outros trabalhos (1911-1913). Edição standard brasileira das obras psicológicas completas de Sigmund Freud, Vol. 12. Disponível em http://conexoesclinicas.com.br/wp-content/uploads/2 015/01/freud-sigmund-obras-completas-imago-vol-12-1911-913.pdf.

FREUD, S. Teoria geral das neuroses (1917). In. Conferências introdutórias sobre Psicanálise - Parte III (1915 - 1916). Edição standard brasileira das obras psicológicas completas de Sigmund Freud, Vol. 16. Disponível em http://conexoesclinicas.com.br/wp-content/uploads/2015/01/freud-sigmund-obras-co mpletas-imago-vol-16-1915-1916.pdf.

FREUD, S. A perda da realidade da neurose e psicose (1924). In: O ego e o id, e outros trabalhos (1923-1925). Edição standard brasileira das obras psicológicas completas de Sigmund Freud, Vol. 14. Disponível em http://conexoesclinicas.com.br/ wp-content/uploads/2015/01/freud-sigmund-obras-completas-imago-vol-19-1923/192 5.pdf. 
GERHARDT, T. E.; SILVEIRA, D. T. Métodos de pesquisa. Universidade Aberta do Brasil - UAB/UFRGS. Porto Alegre: Editora da UFRGS, 2009. Disponível em http://www.ufrgs.br/cursopgdr/downloadsSerie/derad005.pdf.

GIL, A. C. Métodos e técnicas de pesquisa social. São Paulo: Atlas, 6 ed. 2008. Disponível em

https://ayanrafael.files.wordpress.com/2011/08/gil-a-c-mc3a9todos-e-tc3a9cnicas-de-pesquisa -social.pdf.

GODOY, D. A. Musicoterapia, profissão e reconhecimento: uma questão de identidade, no contexto social brasileiro. Revista Brasileira de Musicoterapia. Ano XVI, No 16/2014.

GUERRA, V. O ritmo na vida psíquica: diálogos entre psicanálise e arte. Sociedade Brasileira de Psicanálise de São Paulo. Revista Ide, 2017. Disponível em http://pepsic.bvsalud.org/pdf/ide/v40n64/v40n64a04.pdf.

HERRMANN, M. C. O real na psicose. Instituto de Psicologia - USP. 2004. Disponível em http://www.scielo.br/pdf/pusp/v15n1-2/a25v1512.pdf.

JERUSALINSKY, A. Psicose e autismo na infância: uma questão de linguagem. Psicose Boletim da Associação Psicanalítica de Porto Alegre, ano 4, nº 9, 1993.

JERUSALINSKY, A. O autismo como exclusão do campo do significante. In: Autismo: Intervenção, Clínica e Pesquisa. Revista da Associação Psicanalítica de Curitiba / Associação Psicanalítica de Curitiba, nº 22. 2011.

KUPFER, M. C. Notas sobre o diagnóstico diferencial da psicose e do autismo na infância. Instituto de Psicologia - USP, 2000. Disponível em http://www.sciel o.br/scielo.php?script=sci_arttext\&pid=S0103-65642000000100006.

LACAN, J. O Seminário. Livro 3: As psicoses. Rio de Janeiro: Jorge Zahar, 1985 (Trabalho original publicado em 1955-1956). 
LACAN, J. De uma questão preliminar a todo tratamento possível da psicose. In: Escritos (pp. 537-590). Rio de Janeiro: Jorge Zahar, 1998 (Trabalho original publicado em 1957-1958).

LIMA, T., LERNER, R. Contribuições da noção de pulsão invocante à clínica do autismo e da psicose. Revista Latino Americana de Psicopatologia Fundamental, São Paulo, Dezembro de 2016. Disponível em http://www.scielo.br/pdf/rlpf/v19n4/141 5-4714-rlpf-19-4-0720.pdf.

LIMA, T. Música e invocação: uma oficina terapêutica com crianças com transtornos do desenvolvimento. Universidade de São Paulo. Instituto de Psicologia. São Paulo, 2012. Disponível em https://www.teses.usp.br/teses/disponi veis/47/47131/tde-19092012-123935/publico/1 ima_me.pdf.

LIMA, C. M.; POLI, M. C. Música e um pouco de silêncio: da voz ao sujeito. Revista Ágora, Rio de Janeiro, 2012. Disponível em http://www.scielo.br/pdf/agora/ v15nspe/a02v15nspe.pdf.

MARTINS, P. G., GIARETTA, V. A função subjetivante do ritmo em um contexto de atendimento psicanalítico. Revista Brasileira de Psicoterapia, Vol. 19, 2017. Disponível em file://C:/Users/Usuario/Downloads/v19n2a06.pdf.

Manual diagnóstico e estatístico de transtornos mentais [recurso eletrônico] - DSM-V American Psychiatric Association; tradução: Maria Inês Corrêa Nascimento et al; revisão técnica: Aristides Volpato Cordioli et al - 5. ed. Porto Alegre: Artmed, 2014.

MARFINATI, A. C., ABRÃO, J. L. F. Um percurso pela psiquiatria infantil: dos antecedentes históricos à origem do conceito de autismo. Estilos da Clínica, 2014.

MEYER, G. R., Algumas considerações sobre o sujeito na psicose. Revista Àgora. Rio de Janeiro, 2008. Disponível em http://www.scielo.br/pdf/agora/v11n2/a09 v11n2.pdf.

MOLLOY, C.; FERREIRA, J. Entrevista com Silvia Bleichmar. Revista Psychê. São Paulo, 2001. Disponível em https://www.redalyc.org/pdf/307/30700814.pdf. 
NOGUEIRA, S., MOURA, M. L. Intersubjetividade: perspectivas teóricas e implicações para o desenvolvimento infantil inicial. Revista Brasileira de Crescimento e Desenvolvimento Humano, 2007. Disponível em http://pepsic.bvsalud .org/pdf/rbcdh/v17n2/13.pdf.

OLDFIELD, A. Interactive Music Therapy in Child and Family Psychiatry: Clinical Practice, Researchans Teaching. London and Philadelphia: Jessica Kingsley Publishers, 2006 .

Piazzetta, C. M. F. Análise musical em musicoterapia: uma importante ferramenta para o desenvolvimento do processo terapêutico. Anais do Simpósio de Pesquisa em Música, 108 - 115, Paraná, 2007.

PONTES, Samira; CALAZANS, Roberto. A psicose na CID-10, DSM-IV-TR e DSM-V e o contraponto psicanalítico. Disponível em http://www.scielo.br/pdf/p usp/v28n1/1678-5177-pusp-28-01-00108.pdf.

PUCHIVAILO, M.; HOLANDA, A. A história da musicoterapia na psiquiatria e na saúde mental: dos usos terapêuticos da música à musicoterapia. Revista Brasileira de Musicoterapia, $\quad$ Ano $\quad$ XVI, $2014 . \quad$ Disponível em http://www.revistademusicoterapia.mus.br/wp-content/uploads/2016/10/8-A-HIST\%C 3\%93RIA-DA-MUSICOTERAPIA-NA-PSIQUIATRIA-E-NA-SA\%C3\%9ADE-MENTALDOS-USOS-TERAP\%C3\%8AUTICOS-DA-M\%C3\%9ASICA-\%C3\%80-MUSICOTER APIA-.pdf.

ROSI, F. S., LUCERO, A. Intervenção precoce $\mathbf{x}$ estimulação precoce na clínica com bebês. Tempo Psicanalítico, Rio de Janeiro, v. 50, 2018. Disponível em http://pepsic.bvsalud.org/pdf/tpsi/v50n1/v50n1a09.pdf.

SAMPAIO, R. Por uma nova noção de Música em Musicoterapia. In: Apontamentos em Musicoterapia, São Paulo: Apontamentos, 2005. 
SANTOS, T. C.; OLIVEIRA, Flávia L. C. Teoria e clínica psicanalítica da psicose em Freud e Lacan. Disponível em http://www.scielo.br/scielo.php?script=sci_artt ext\&pid=S1413-73722012000100009.

SEINCMAN, M. O psicanalista, o autista e o autismo. Revista Latino Americana de Psicopatologia Fundamental, 1997. Disponível em http://www.scielo.br/pdf/rlpf/v3 n1/1415-4714-rlpf-3-1-0117.pdf.

SILVA, E. Mecanismos de defesa do ego. O portal dos psicólogos, 2010. Disponível em https://www.psicologia.pt/artigos/textos/TL0212.pdf.

SOUZA, M. B. et al. Da vibração ao encontro com o outro: psicanálise, música e autismo. Revista Estilos da Clínica. São Paulo, 2017. Disponível em http://pe psic.bvsalud.org/scielo.php?script=sci_arttext\&pid=S1415-71282017000200006.

TENÓRIO, Fernando. Psicose e esquizofrenia: efeitos das mudanças nas classificações psiquiátricas sobre a abordagem clínica e teórica das doenças mentais. Disponível em http://www.scielo.br/pdf/hcsm/v23n4/0104-5970-hcsm-S010 4-59702016005000018.pdf.

VALENTIN, F., SÁ, L. C., ESPERIDIÃO, E. Práticas musicoterapêuticas em grupo: planejar para intervir. Revista Brasileira de Musicoterapia Ano XV n 15, 2013. Disponível em http://www.revistademusicoterapia.mus.br/wp-content/upl oads/2016/10/8-PR\%C3\%81TICAS-MUSICOTERAP\%C3\%8AUTICAS-EM-GRUPO. pdf. 